\title{
Uma ferramenta para diagnóstico de (in)sucesso acadêmico: um estudo de caso do curso de bacharelado em Tecnologia da Informação
}

\section{A tool for the diagnosis of academic (un)success: a case study of the bachelor's degree in Information Technology}

\author{
Pedro Paulo Dantas Franco Rocha ${ }^{1 *}$, Samara Martins Nascimento ${ }^{1}$, Reudismam Rolim de
} Sousa $^{1}$

\section{RESUMO}

Um problema recorrente em Instituições de Ensino Superior é a evasão estudantil, a qual é ocasionada devido a diferentes motivações, como trabalho, difícil metodologia, entre outros. Esta problemática gera consequências pessoais, profissionais e econômicas. Alguns dos cursos que passam por esse obstáculo são os cursos da área de Tecnologia da Informação. Para entender a problemática, é possível verificar essas informações através de tecnologias computacionais, como na construção de ferramentas capazes de revelar a situação dos alunos em determinadas disciplinas e, de posse dessas informações, elaborar estratégias que permitam resolver ou reduzir evasões ou abandonos. A fim de contribuir acerca do conhecimento dos dados relacionados à Universidade Federal Rural do Semi-Árido e compreender como está atualmente o curso de Bacharelado em Tecnologia da Informação, este presente trabalho é proposto. Assim, será desenvolvida uma ferramenta para visualização de dados, que possibilite aos gestores da educação a análise com precisão e eficiência da situação dos alunos do curso validado, permitindo que os mesmos tenham melhorias no processo de tomadas de decisões para resolução de problemas.

Palavras-chave: Análise de Dados; Visualização de Informações; Evasão; Ensino Superior;

\begin{abstract}
A recurrent problem in Higher Education Institutions is student dropout, which is caused by different motivations, such as work, difficult methodology, among others. This problem generates personal, professional and economic consequences. Some of the courses that go through this obstacle are courses in the Information Technology area. In order to understand the problem, it is possible to verify this information through computational technologies, as in the construction of tools capable of revealing the situation of students in certain subjects and, with this information, develop strategies to solve or reduce dropouts or dropouts. In order to contribute to the knowledge of data related to the Federal Rural University of the Semi-Arid and to understand how the Bachelor's Degree in Information Technology is currently doing, this present work is proposed. Thus, a data visualization tool will be developed, enabling education managers to accurately and efficiently analyze the situation of students in the validated course, allowing them to improve the decision-making process for problem solving.
\end{abstract}

Keywords: Data Analysis; Information Visualization; Evasion; Higher Education;

\footnotetext{
${ }^{1}$ Universidade Federal Rural do Semi-Árido

*E-mail: ppdfr84@gmail.com
} 


\section{INTRODUÇÃO}

As frequentes melhorias e a alta demanda por profissionais na área de Tecnologia da Informação (TI) têm estimulado as Instituições de Ensino Superior (IES) a investirem em cursos voltados ao setor. Segundo o INEP (Instituto Nacional de Estudos e Pesquisas Educacionais Anísio Teixeira), cerca de 53 mil estudantes se formaram no Ensino Superior em cursos da área de TI, no ano de 2019 (NOVA, 2021).

Um problema antigo do ensino superior brasileiro, que perdura até os dias atuais e atinge praticamente todos os cursos, é a evasão de estudantes, conforme Hipólito (2011). Ainda segundo ele, esse problema causa algumas consequências, como a formação de profissionais abaixo da capacidade esperada, frustração dos alunos que não conseguem concluir sua graduação e significativo desperdício de recursos. Com os cursos de TI não é diferente, segundo a Associação das Empresas de Tecnologia da Informação e Comunicação e de Tecnologias Digitais (Brasscom), além dos cursos desse setor ainda possuírem uma baixa procura e poucas matrículas, há um alto índice de evasão, em que $39 \%$ dos alunos da rede privada e $26,6 \%$ da rede pública abandonam o curso (NOVA, 2021).

No curso de Bacharelado em Tecnologia da Informação (BTI) da Universidade Federal Rural do Semi-Árido (UFERSA), além do problema da evasão, existe também o de egressos e retenções. Dessa forma, através de ferramentas que permitam o monitoramento da "saúde" dos cursos, acredita-se que podem resolver, ou pelo menos reduzir consideravelmente, o número de insucessos dos discentes nas disciplinas do curso de BTI. Sabendo disso, este trabalho tem como objetivo o desenvolvimento de uma ferramenta para visualização de dados, também chamada de dashboard, que exiba, através de tecnologias web e banco de dados, indicadores relacionados à situação dos estudantes nas várias disciplinas ofertadas pelo curso de BTI na UFERSA, permitindo que, ciente desses dados, os gestores possam tomar decisões que sanem e incentivem os estudos em disciplinas com esses problemas. 


\section{TRABALHOS RELACIONADOS}

Esta seção elenca alguns trabalhos que tem uma proposta semelhante à esta pesquisa.

Gomes (2018) discute a importância da implementação de dashboards para ajudar organizações educacionais a tomarem decisões estratégicas, devido esse tipo de ferramenta possuir grande eficácia na apresentação de dados, dado que ocorre de forma simples e ainda possibilita a inserção de diferentes recursos interativos, que proporcionam ao usuário uma filtragem melhor dos dados. O objetivo do dashboard proposto é que ele possibilite apresentar as informações provenientes do sistema web utilizado pela universidade, de forma resumida, facilitando assim, a tarefa de gestão.

Já Rezende (2019), percebendo a falta de contato do professor com o aluno nos cursos de graduação e pós-graduação em regime de ensino a distância, e que isso, por consequência, prejudica a compreensão do docente em relação a evolução e absorção dos conteúdos pelos discentes, propõe um modelo de criação de dashboards para apoio à avaliação de estudantes em ambiente de ensino à distância, permitindo assim, que os professores envolvidos no contexto do ensino online possam, através de indicadores acompanhar o desenvolvimento dos discentes em suas disciplinas.

Por outro lado, Kraemer (2018), analisando o problema dos altos índices na taxa de evasão nos cursos superiores, sugere, através de ferramentas computacionais, a obtenção de um algoritmo para detectar padrões, correlações e comportamentos nos dados gerados sobre os alunos das IES e, a partir daí, desenvolver um sistema de BI (Business Intelligence) para criar um Sistema de Apoio à Decisão que possa auxiliar os gestores das IES na hora de tomar decisões.

\section{UM AMBIENTE PARA VISUALIZAÇÃO DA SITUAÇÃO DOS ALUNOS DE BTI}

Nesta seção será apresentado o desenvolvimento do ambiente para visualizar os indicadores relacionados à situação dos alunos do curso de BTI na UFERSA, Campus Pau dos Ferros, baseado em dashboard. 


\section{DASHBOARD}

Este dashboard é um painel para visualização de informações, que tem controle intuitivo, cujos dados são apresentados, em uma tela com informações gráficas, todas elas com dados provenientes das planilhas geradas pelo Sistema Integrado de Gestão de Atividades Acadêmicas (SIGAA) da UFERSA, Campus Pau dos Ferros, do curdo de BTI, de forma que é possível monitorar e visualizar esses dados de forma ágil.

Na Figura 1 pode ser vista a tela inicial do dashboard, composta dois elementos:

- Elemento 1 - Sidebar: esse elemento trata-se de um menu vertical, que possibilita ao usuário selecionar qual tipo de informação da base de dados pretende visualizar os detalhes, sendo elas: Alunos por CH Cumprida; Ingressos, egressos e retenções (IER); e insucessos.

- Elemento 2 - Área dos gráficos: nesse elemento, são apresentados todos os gráficos possíveis plotados com as informações provenientes do banco de dados selecionado.

Figura 1 - Tela inicial do ambiente

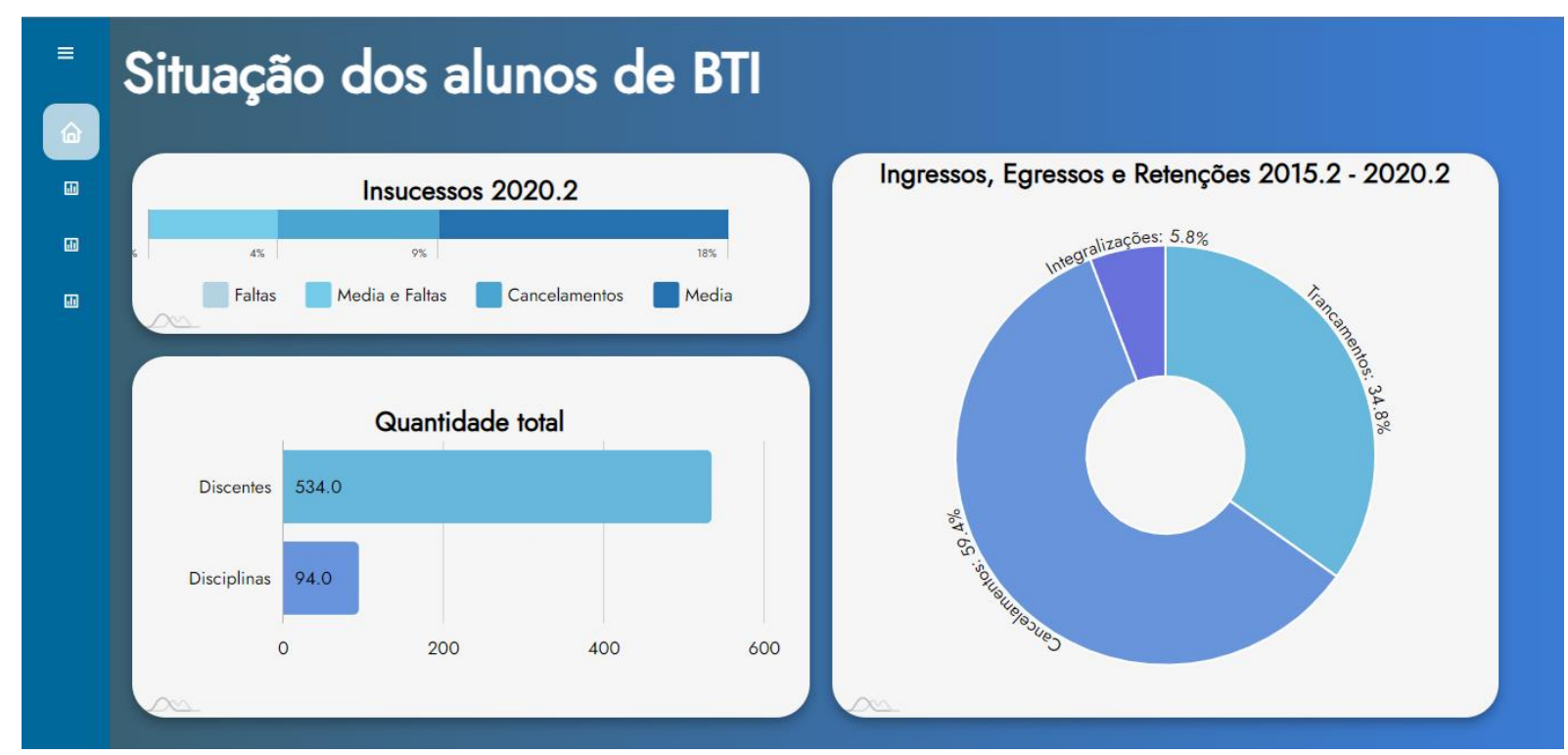

Fonte: Autores (2021) 
Cada gráfico pertencente à Figura 1 é detalhado a seguir. Na Figura 2, tem-se um gráfico de progresso, onde são apresentados os insucessos dos alunos. Para esse caso, os dados apresentados são referentes ao período 2020.2. Essa plotagem contém informações relacionadas à quantidade total de reprovações por faltas, média, média e faltas e os cancelamentos dos discentes nesse referido período. Observando o gráfico, é possível perceber que em 2020.2, nenhum dos alunos reprovaram apenas por falta, $4 \%$ reprovaram por média e falta, $18 \%$ apenas por média e $9 \%$ cancelaram disciplinas.

Figura 2 - Insucessos 2020.2

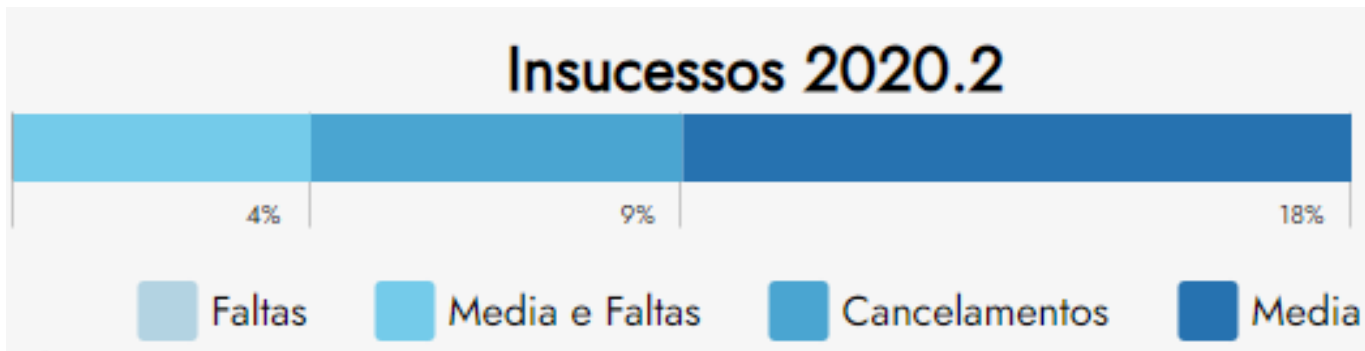

Fonte: Autores (2021)

Na Figura 3, em formato de pizza, é possível visualizar os dados referentes à quantidade de ingressos, egressos e retenções registrados desde o período 2015.2 até o período 2020.2. Analisando o gráfico, nota-se que nesse intervalo de tempo, 5,8\% dos discentes foram integralizados, 34,8\% realizaram o trancamento do programa e 59,4\% o cancelamento. Isso significa que a quantidade de insucessos nos programas é amplamente superior à quantidade de sucessos. 
Figura 3 - Ingressos, Egressos e Retenções 2015.2 à 2020.2

\section{Ingressos, Egressos e Retenções 2015.2 - 2020.2}

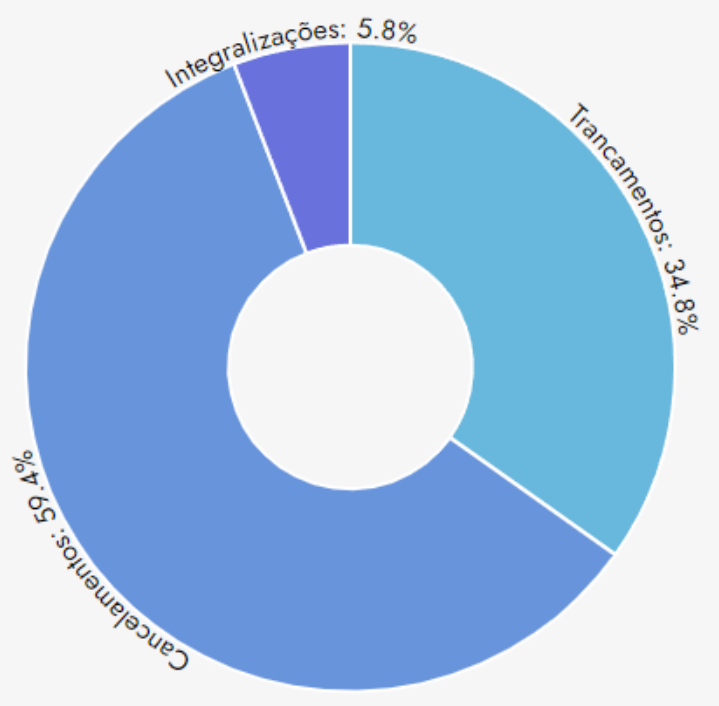

Fonte: Autores (2021)

Na Figura 4, no formato de barras, é apresentada a quantidade total de discentes (ativos e não ativos) e de disciplinas ofertadas, desde o período 2015.2 até o período 2020.2. Visualizando o gráfico, percebe-se que até esse período o número de discentes é de 534 e que o curso dispõe de 94 disciplinas.

Figura 4 - Quantidade total de discentes e disciplinas

\section{Quantidade total}

\section{Discentes}

534.0

Disciplinas

94.0

0 
Uma outra tela mostrada no dashboard é a de Alunos com percentual de carga horária $(\mathrm{CH})$ cumprida, conforme mostrada na Figura 5, que contém informações iniciais do dashboard, quando o usuário seleciona, na sidebar, a base de dados "CH Cumprida". Após o usuário realizar a escolha, são apresentadas na tela gráficos com informações relacionadas a base desejada.

Figura 5 - Tela Alunos com percentual de CH. cumprida

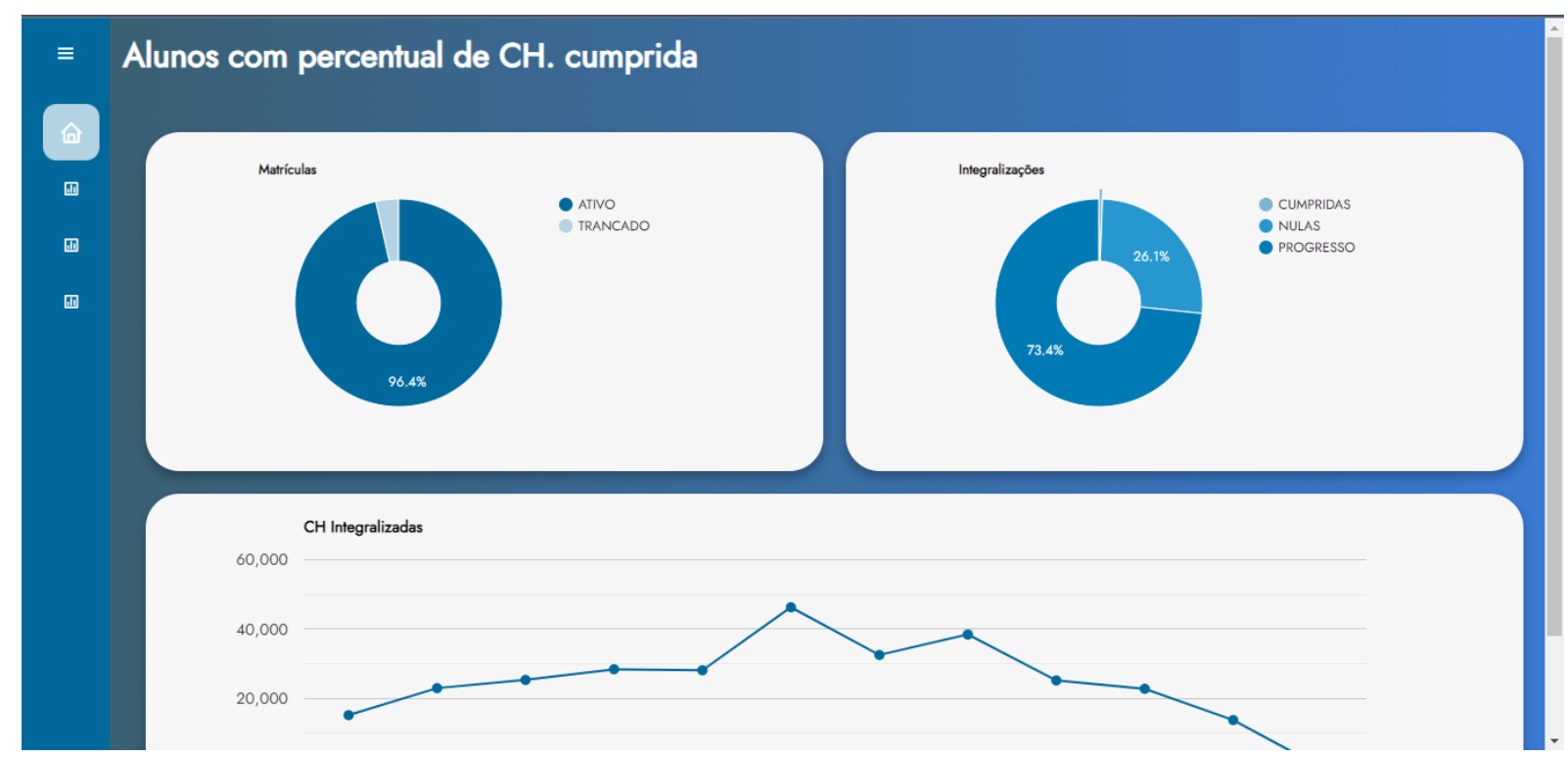

Fonte: Autores (2021)

Cada gráfico da Figura 5 é mostrado individualmente a seguir. A Figura 6 apresenta ao usuário a quantidade de alunos que estão com a sua matrícula ativa ou trancada. Dessa forma, as informações mostram que, dos 534 discentes, 19 estão com a matrícula trancada, o que corresponde a 3,6\%, e 96,4\% estão com o status ativo. 
Figura 6 - Matrículas

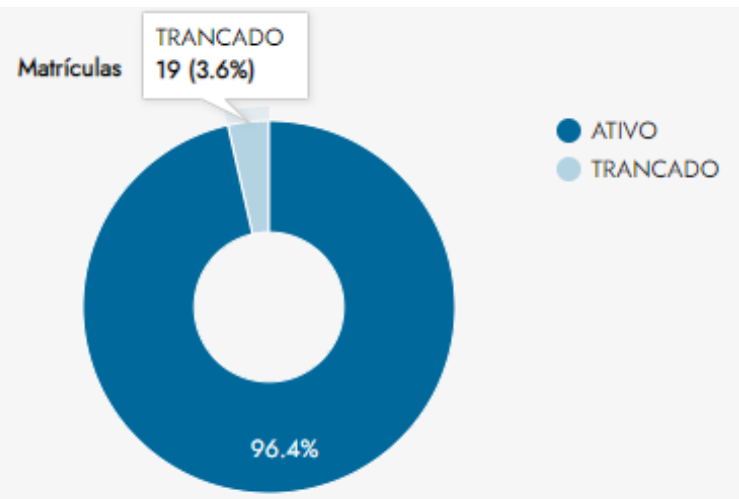

Fonte: Autores (2021)

Já na Figura 7 é possível ver o resultado gráfico acerca da quantidade de discentes que estão integralizados, em progresso ou com a integralização nula. Notando o gráfico em forma de pizza, vê-se que apenas $0,6 \%$ do alunos estão com $100 \%$ ou mais da carga horária cumprida, 73,4\% estão ainda em andamento, ou seja, com mais de $0 \%$, porém com menos $100 \%$ da carga horária, e $26,1 \%$ estão com a carga horária nula (0\%) (i.e. os discentes estão com a $\mathrm{CH}$ igual a $0 \%$, ou seja aqueles que ingressaram no curso e não finalizaram qualquer disciplina).

Figura 7 - Integralizações

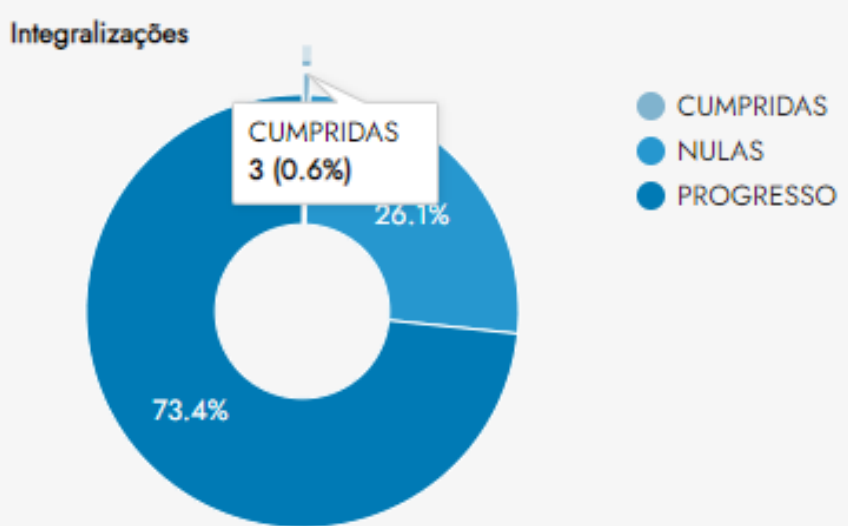

Fonte: Autores (2021) 
Na Figura 8 é possível ver o somatório de todas as cargas horárias dos discentes ingressantes de um determinado período. Analiticamente, o período 2018.2 é o que possui uma maior soma de integralizações, resultando um total de 46.290.

Figura 8 - Cargas horárias integralizadas

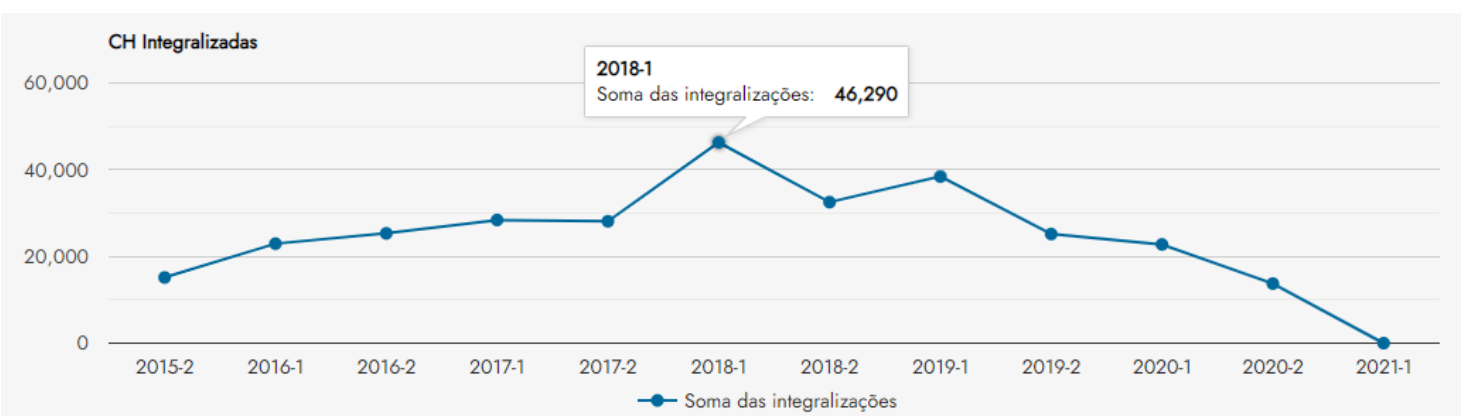

Fonte: Autores (2021)

Outra informação mostrada no painel de visualizações, para permitir a análise dos dados é apresentada na Figura 9, que elenca as informações acerca da base de dados relacionadas aos "Ingressos, egressos e retenções". Os dados obtidos via SIGAA possibilitaram a geração de cinco diferentes gráficos: ingressos, ativos, integralizações, trancamentos e cancelamentos, os quais são detalhados a seguir.

Figura 9 -Tela Ingressos, egressos e retenções

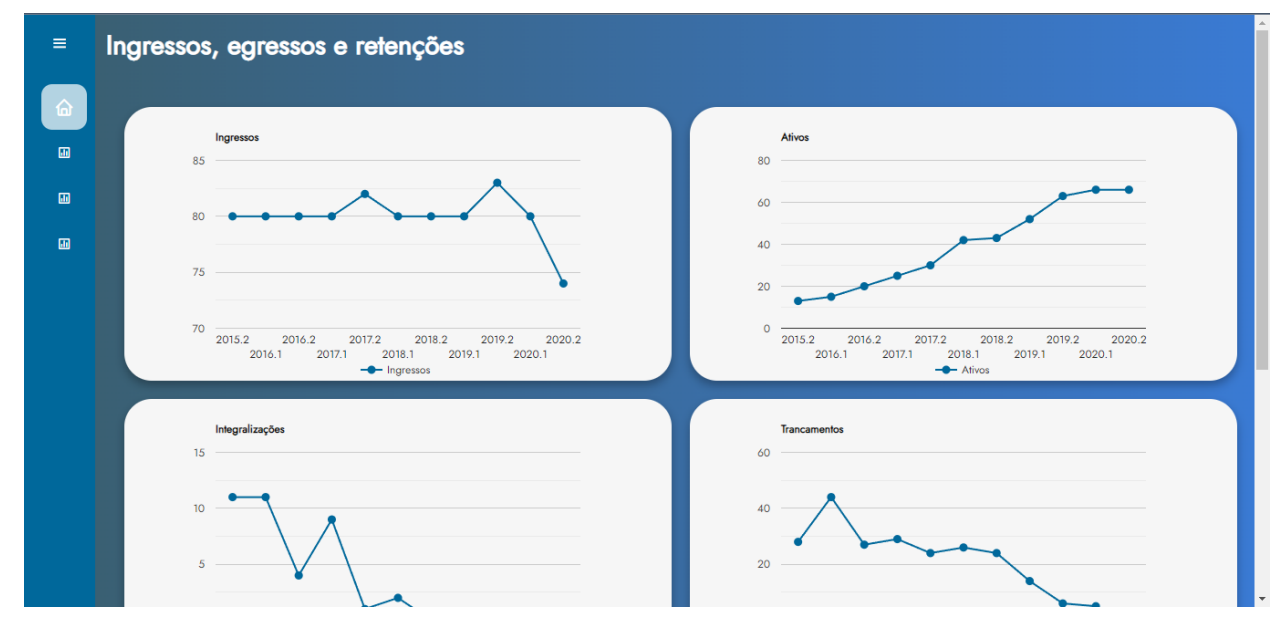

Fonte: Autores (2021) 
A Figura 10 é um gráfico de linhas, em que é possível visualizar a quantidade de discentes que ingressaram em cada período. Dessa forma, é perceptível que de 2015.2 até 2019.1 o número de ingressantes permaneceu constante, somando 80 ingressos, com exceção do período 2017.2, que registrou 82 ingressantes. O período 2019.2 foi o que contou com mais ingressos, chegando a 83. Em 2020.1 esse número voltou para 80, e em 2020.2 houve um declínio para 74 .

Figura 10 - Ingressos

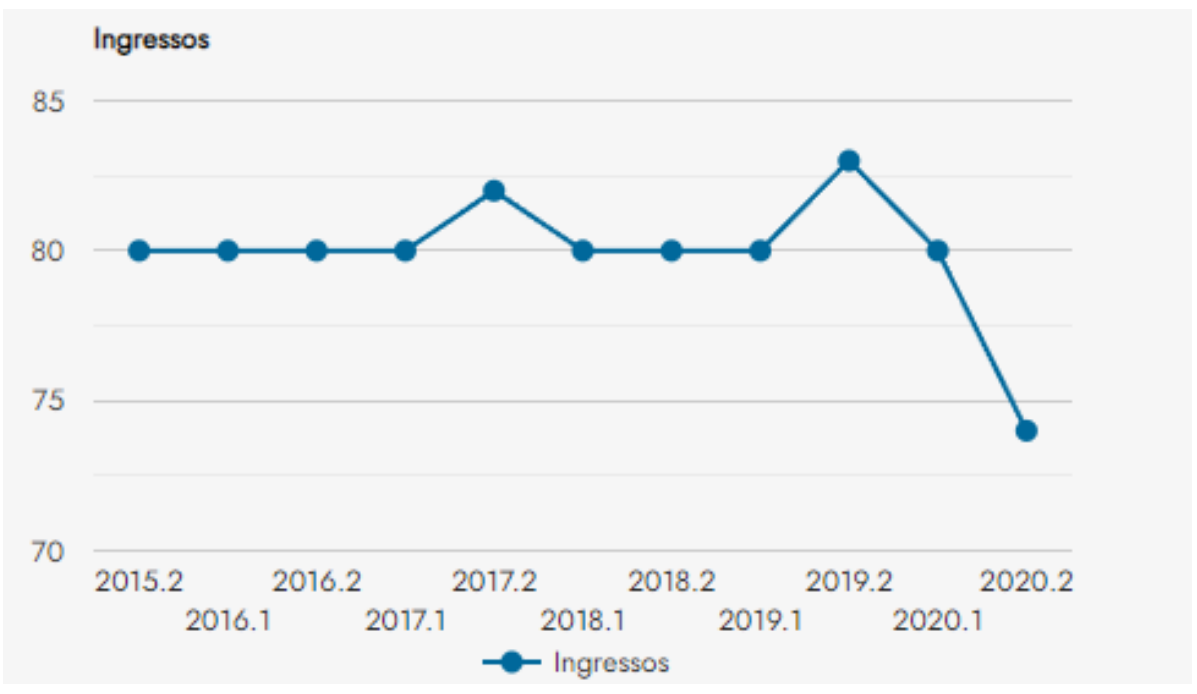

Fonte: Autores (2021)

Na Figura 11 é plotado um gráfico de linhas que mostra a quantidade de alunos ingressantes de cada período que continuam ativos no programa. Sendo assim, é perceptível que o gráfico apresenta uma crescente, onde a cada período o número de discentes ativos cresce, começando com 13 ativos em 2015.2 e 66 em 2020.2. 
Figura 11 - Ativos

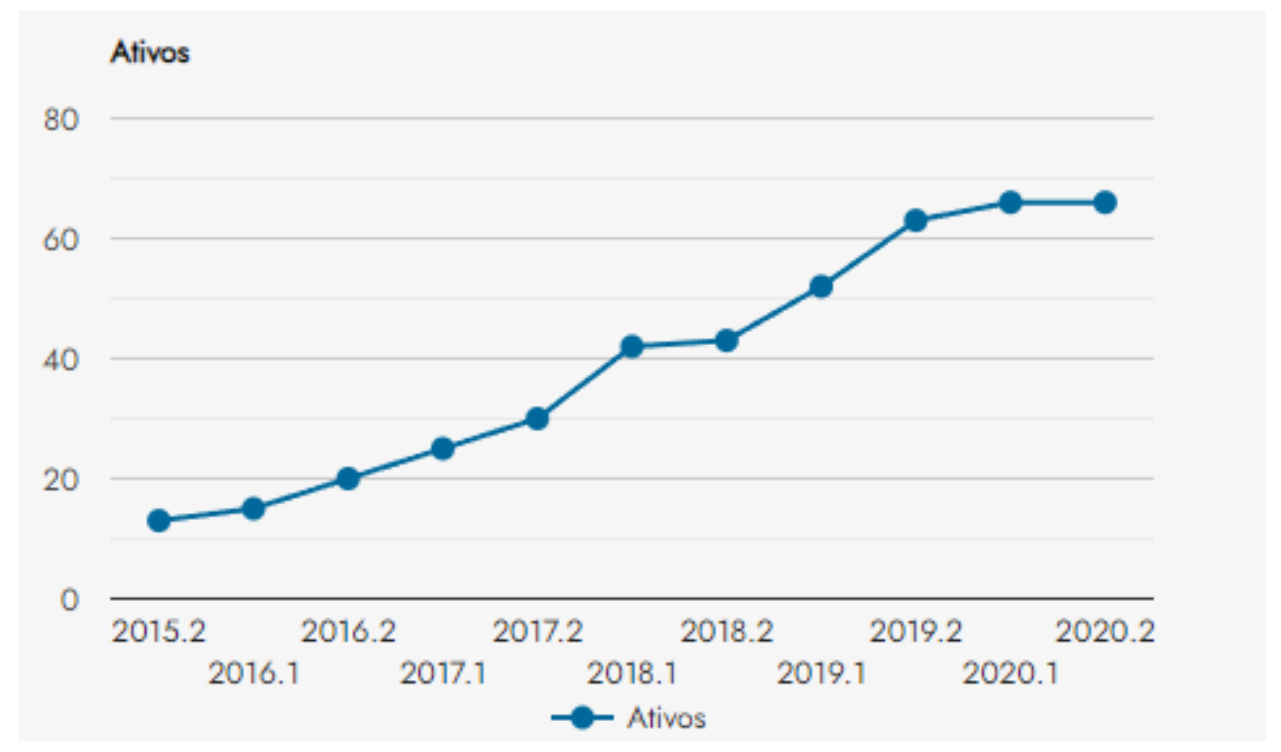

Fonte: Autores (2021)

Na Figura 12, é plotada a quantidade de alunos ingressantes em um período que estão integralizados. Assim, os períodos que mais possuíram alunos integralizados foram os de 2015.2 e 2016.1, somando 11 integralizações. Após isso, em 2016.2 houve uma queda para 4 alunos. Em 2017.1, esse número voltou a crescer, saltando para 9. No período de 2017.2, voltou a cair, ficando com apenas uma integralização, em 2018.1 houve um ligeiro aumento para duas, até que de 2018.2 a 2020.2 não houve discentes integralizados. Esse comportamento é natural, visto que os discentes dos períodos iniciais do curso estão a mais tempo na graduação e consequentemente, possuem um tempo maior para concluir as disciplinas. 
Figura 12 - Integralizações

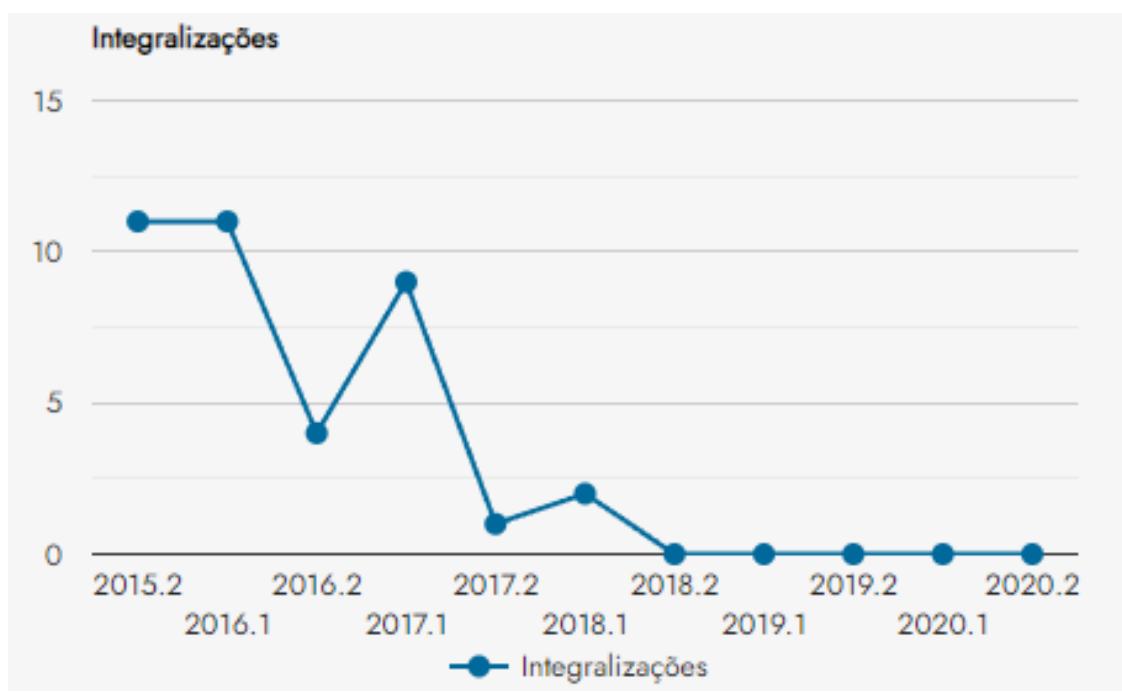

Fonte: Autores (2021)

Já na Figura 13 podem ser vistos os trancamentos de programa que os alunos ingressantes de cada período realizaram. Observando o gráfico, pode-se perceber que houveram 28 trancamentos em 2015.2. Esse número subiu para 44 em 2016.1. Em 2016.2, esse número caiu para 27; em 2017.1, subiu para 29; em 2017.2 reduziu para 24 e, em 2018.1, subiu para 26. A partir do período 2018.2, começou um declínio no número de trancamentos que foi até o período de 2020.2, saindo de 24 para 0.

Figura 13 - Trancamentos

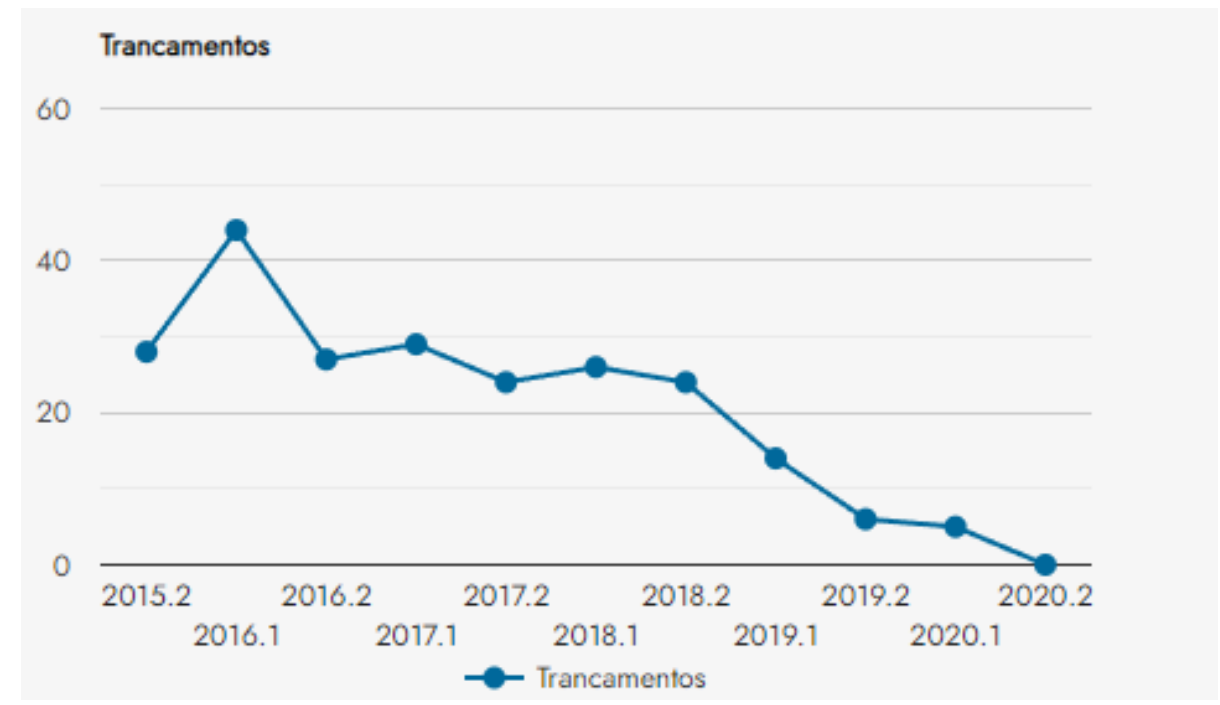

Fonte: Autores (2021) 
Na Figura 14 pode ser visto o total de cancelamentos, também em forma de linhas. No gráfico percebe-se a quantidade de alunos que ingressaram em um determinado período. Os resultados indicam que os períodos em que possuiu mais discentes que cancelaram foram os de 2015.2 e 2016.2. A partir de 2017.2, houve uma queda no número, saindo de 51 cancelamentos para 9, que corresponde ao período 2020.1. Em 2020.2, esse número permaneceu estável.

Figura 14 - Cancelamentos

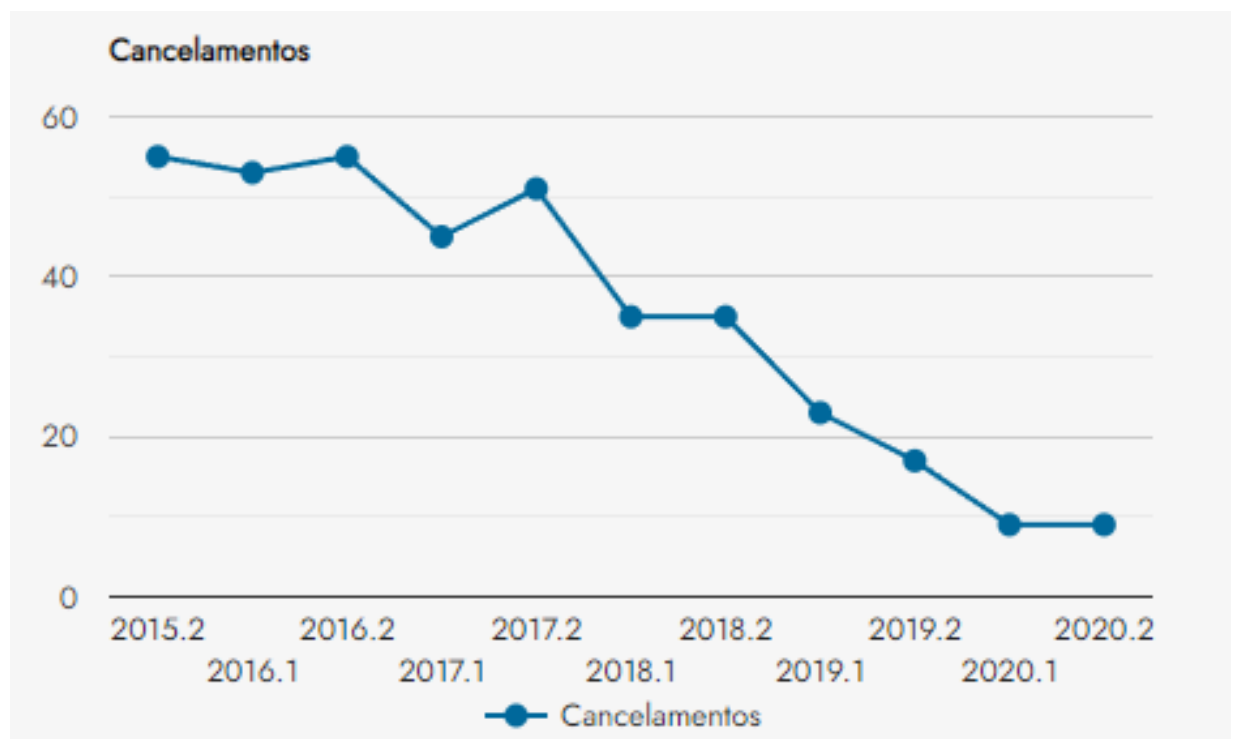

Fonte: Autores (2021)

Na Figura 15 pode ser vista a tela dos casos de Insucessos de Alunos, mostrando, de forma geral, os insucessos que os alunos obtiveram em cada disciplina ofertada por curso e período. No caso do exemplo, os casos de insucessos são mostrados para o curso de BTI, no período de 2020.2. Nesta tela, são apresentados dois elementos: o primeiro, intitulado "Consultar turmas" (Figura 24), permite fazer a consulta de cada turma individualmente. Já o segundo elemento é a área em que são apresentados os gráficos, que serão demonstrados a seguir. 
Figura 15 - Tela Insucessos de alunos

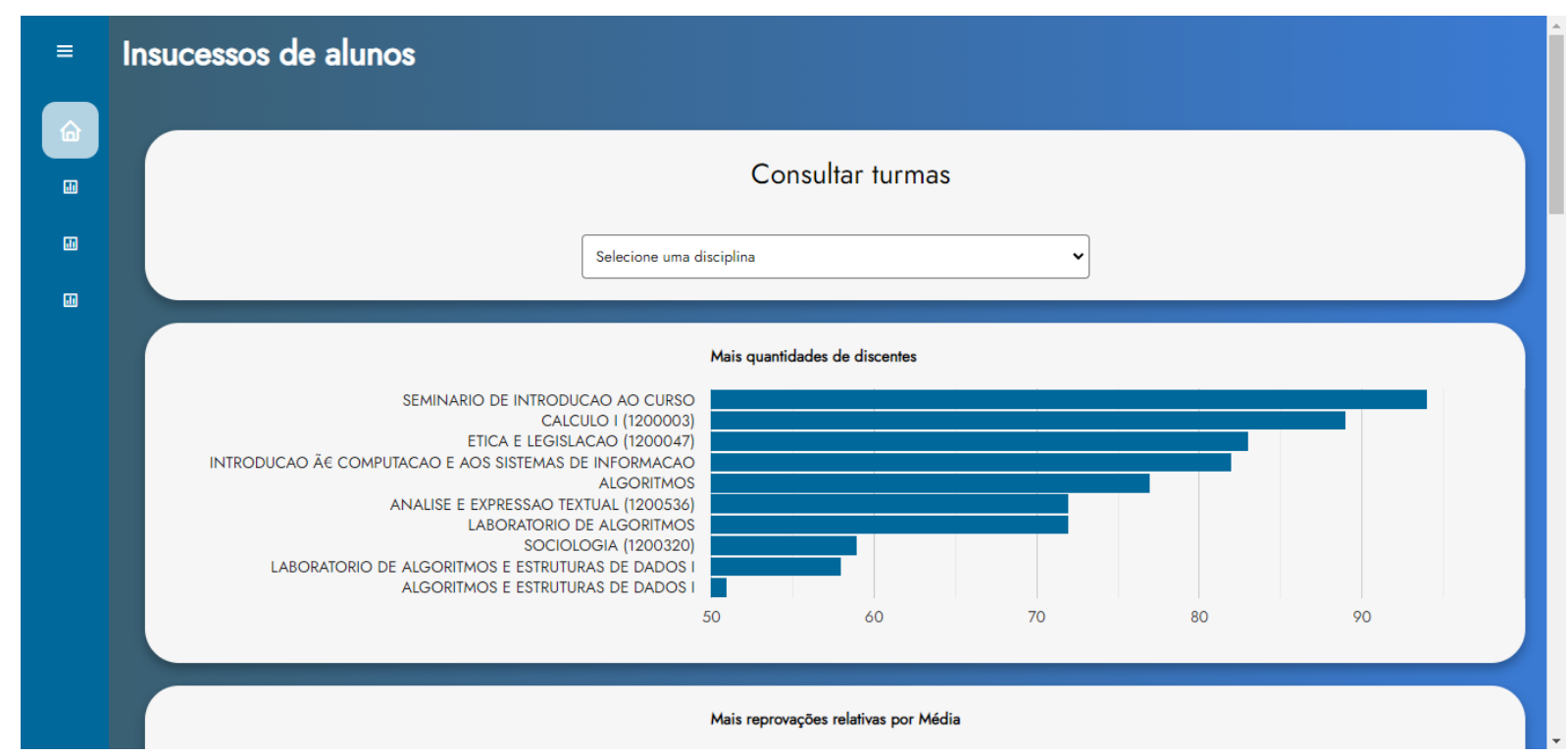

Fonte: Autores (2021)

Na Figura 16 é apresentado um ranking com as dez disciplinas que mais têm discentes matriculados, em que é possível perceber que a disciplina que mais tem alunos matriculados é a de Seminário de Introdução ao Curso, com 94 discentes e a que conta com um menor número é a de Algoritmos e Estruturas de Dados I, com apenas 48 discentes matriculados.

Figura 16 - Quantidades de discentes

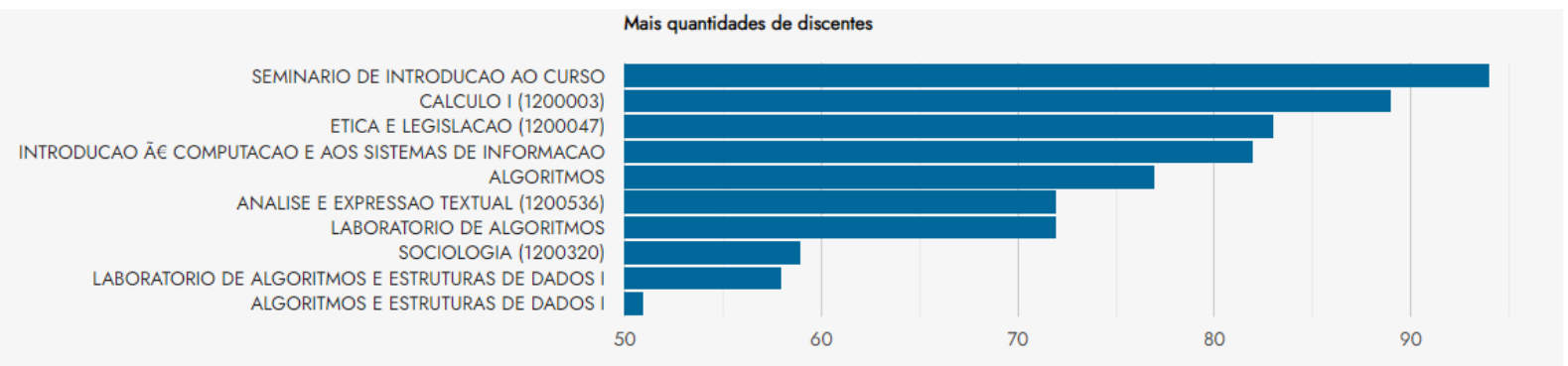

Fonte: Autores (2021)

Na Figura 17 é possível ver as 10 disciplinas que mais reprovaram alunos por média. Nessa exibição de resultados, esse gráfico foi construído levando em consideração as quantidades de reprovações relativas por média. Nesse caso, os dados apresentados 
indicam que no semestre 2020.2, a disciplina de Cálculo I (1200003) foi a que mais reprovou (com 39 reprovações) e a disciplina de Ética e Legislação (1200047) foi a que menos reprovou, com apenas uma desaprovação.

Figura 17 - Reprovações relativas por média

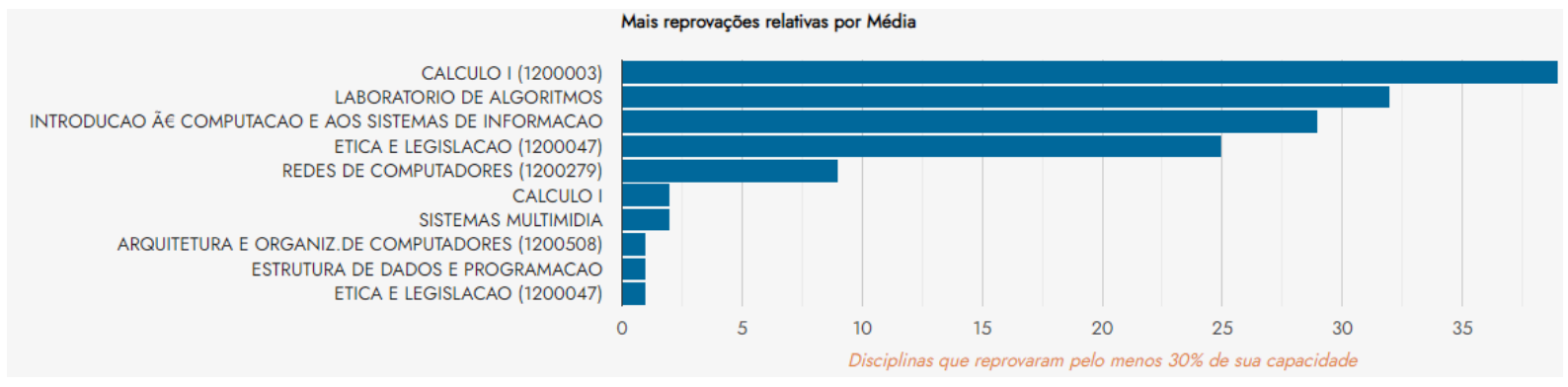

Fonte: Autores (2021)

Já na Figura 18 podem ser vistas as 10 disciplinas que mais reprovaram por média e, nesse caso, não leva em consideração a capacidade da turma. Sendo assim, considerase apenas o número absoluto de reprovações que cada disciplina obteve. Os dados apresentados indicam que a disciplina de Cálculo I (1200003) permanece sendo a primeira ranqueada (com 39 reprovações). Já em última colocação, é apresentada a disciplina de Algoritmos e Estruturas de Dados I, como sendo a que menos reprovou, com 8 reprovações.

Figura 18 - Reprovações absolutas por média

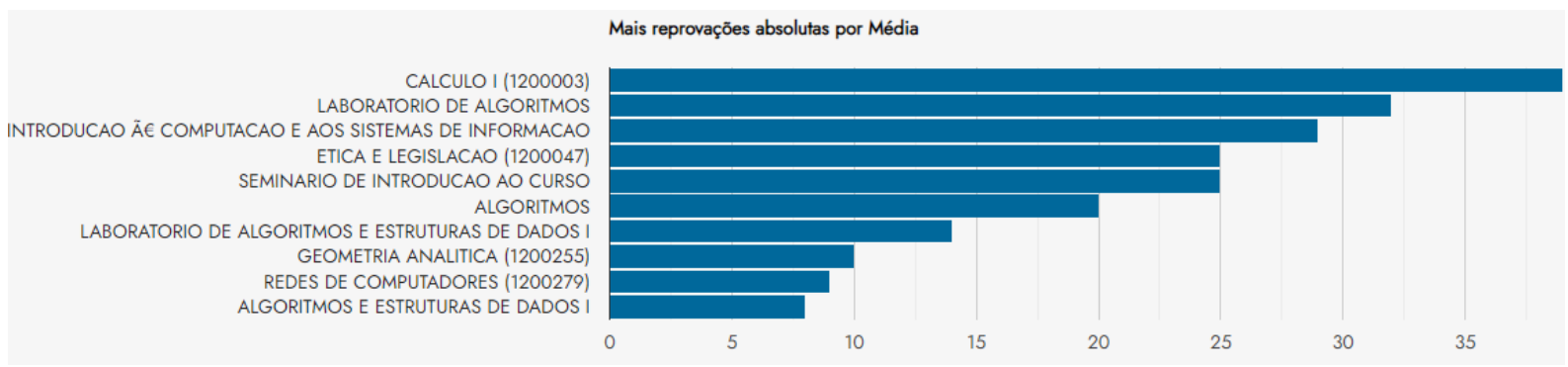

Fonte: Autores (2021) 
No gráfico da Figura 19 é mostrado ao usuário as disciplinas que mais reprovaram apenas por falta. Este gráfico foi programado para também apresentar as 10 disciplinas que mais reprovaram por esse quesito. Porém, como o número de componentes curriculares foi baixo, apenas três disciplinas são apresentadas nos resultados, são elas: Sistemas Operacionais, Banco de Dados e Sistemas Distribuídos, com 2, 1 e 1 insucessos, respectivamente.

Figura 19 - Reprovações por falta

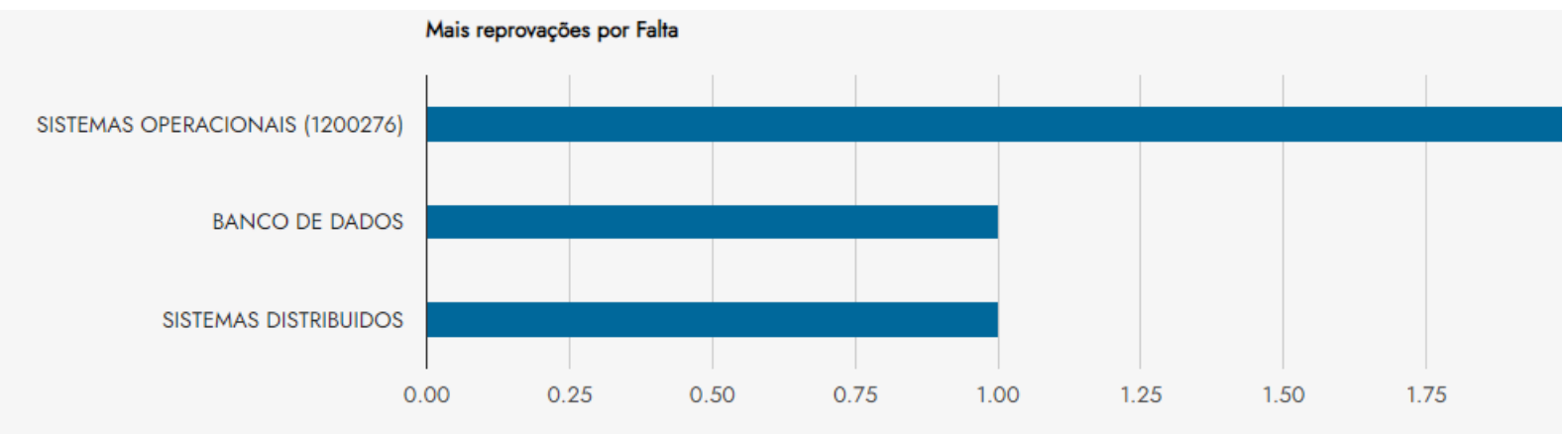

Fonte: Autores (2021)

Já no gráfico da Figura 20 podem ser vistas as 10 matérias que mais reprovaram por média e também por falta, simultâneamente. Os resultados indicam que a disciplina de Análise e Expressão Textual (1200536) foi a que apresentou maior número de reprovados, somando 20 alunos, e Álgebra Linear, Banco de Dados e Engenharia de Software foram as que menos reprovaram nessa modalidade, cada uma com uma reprovação apenas.

Figura 20 - Reprovações por média e falta

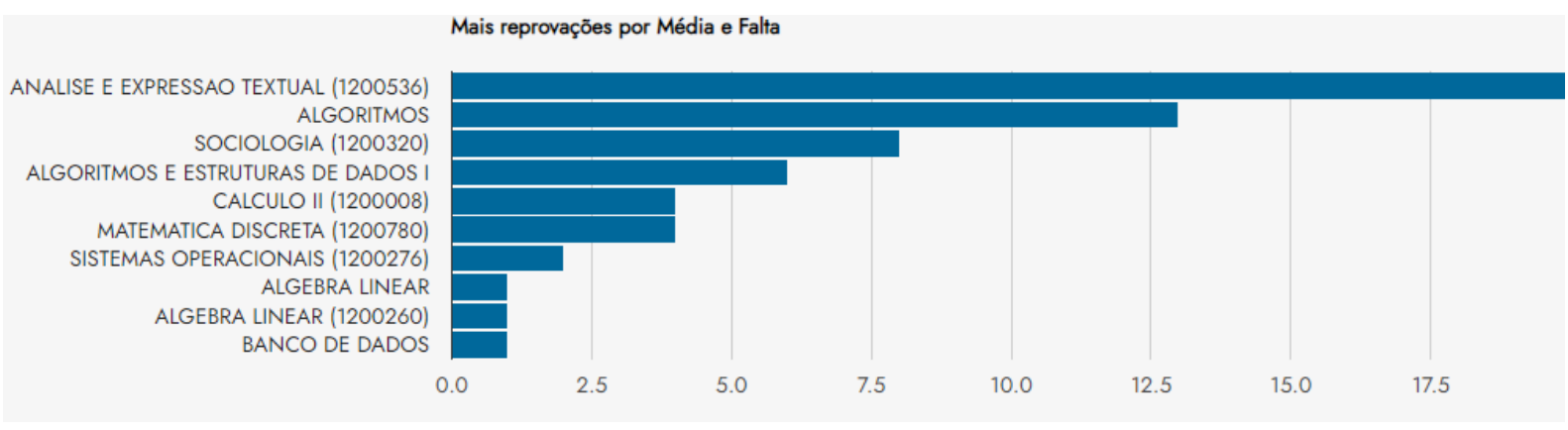

Fonte: Autores (2021) 
Na Figura 21 são apresentadas as disciplinas que mais obtiveram cancelamentos. Para este caso, foi levado em conta o quantitativo de alunos de cancelamentos relativos, ou seja, as informações foram geradas considerando a capacidade da turma. O gráfico foi programado para plotar as 10 disciplinas que mais foram canceladas, porém, como o número de cancelamentos foi baixo, apenas as disciplinas de Matemática Discreta (1200780), Eletricidade e Magnetismo, Geometria Analítica e Introdução às Funções de Várias Variáveis apareceram.

Figura 21 - Cancelamentos relativos

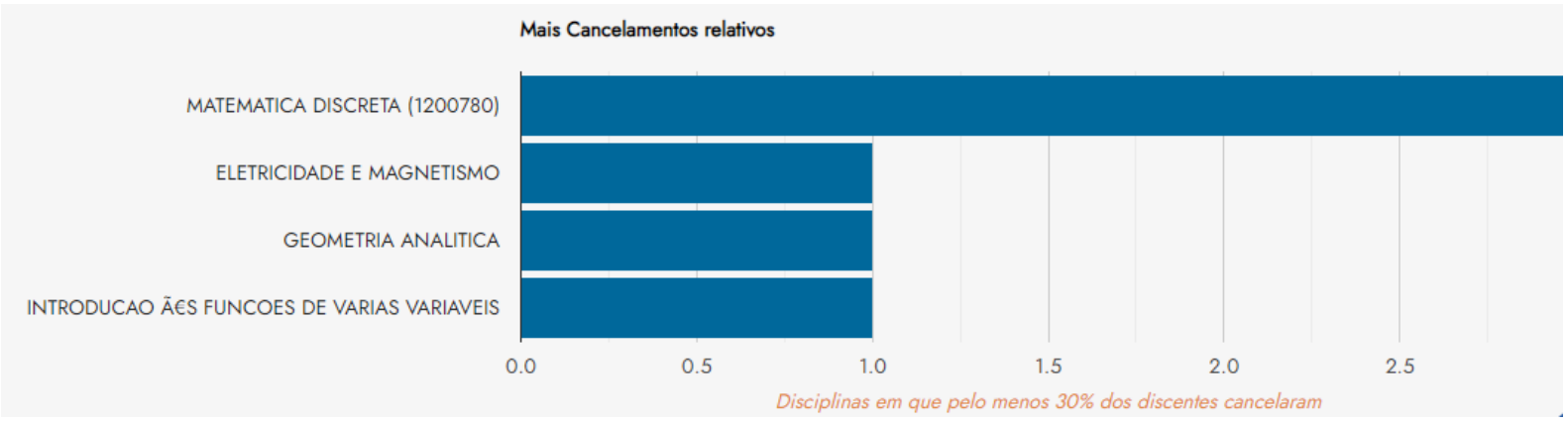

Fonte: Autores (2021)

Na Figura 22 pode-se ver os 10 componentes curriculares que possuíram uma maior taxa de cancelamentos por parte dos discentes. Segundo a plotagem, Cálculo I (1200003) foi a disciplina mais cancelada, contando com 12 cancelamentos, já Administração e Empreendedorismo a menos, com apenas 6 cancelamentos.

Figura 22 - Cancelamentos absolutos

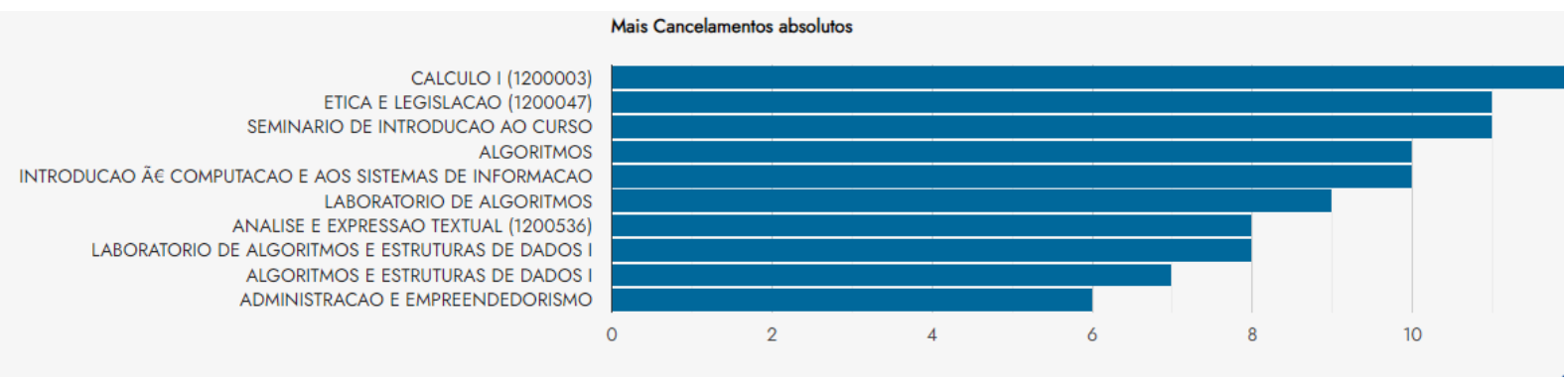

Fonte: Autores (2021) 
A Figura 23 apresenta um ranking geral, em que é possível ver as 10 disciplinas que mais obtiveram insucessos nos quesitos dos gráficos anteriores. De acordo com o resultado gráfico apresentado, a disciplina de Cálculo I (1200003) foi o componente que mais obteve insucessos (51 insucessos) e Sociologia (1200320), a que menos contou com não sucessos de alunos (15).

Figura 23 - Insucessos

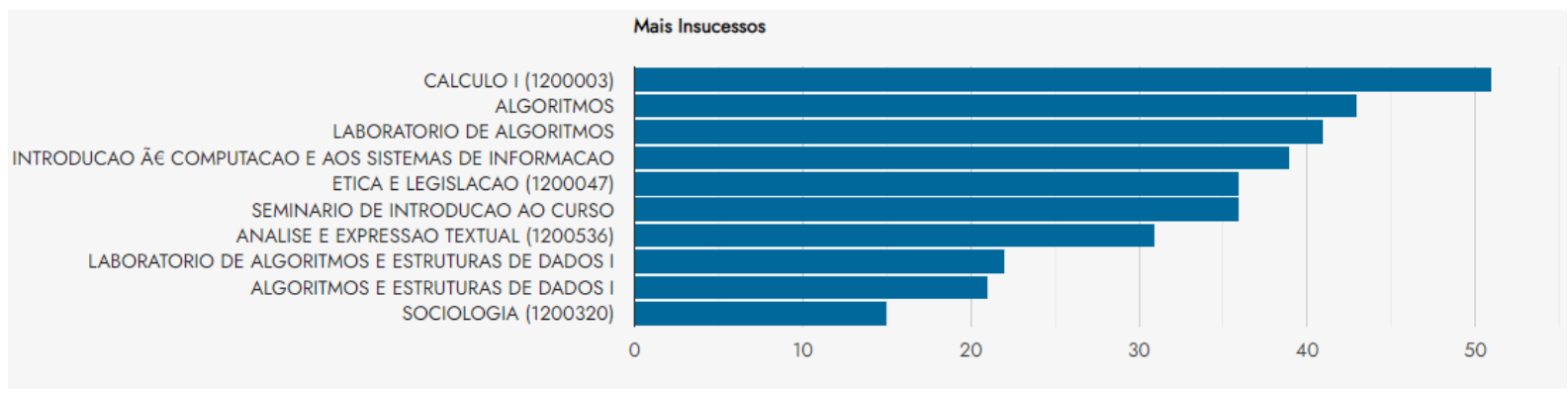

Fonte: Autores (2021)

Na Figura 24 pode ser visto o primeiro elemento da tela de Insucessos de alunos (Figura 15), citado anteriormente. Essa função permite ao usuário consultar informações de uma determinada turma individualmente.

Quando o usuário clica na caixa "Selecione uma disciplina”, é aberta uma opção com todas as disciplinas disponíveis que o curso de BTI oferece. Assim, o usuário poderá escolher de qual componente deseja visualizar as informações separadamente. A demonstração desse recurso é feita na Figura 24. 
Figura 24 - Consultar turmas

\section{Consultar turmas}

Selecione uma disciplina

Selecione uma disciplina

ADMINISTRACAO E EMPREENDEDORISMO

ALGEBRA LINEAR

ALGEBRA LINEAR (1200260)

ALGORITMO E PROGRAMACAO I

ALGORITMOS

ALGORITMOS E ESTRUTURAS DE DADOS I

ALGORITMOS E ESTRUTURAS DE DADOS ॥

ANALISE E EXPRESSAO TEXTUAL (1200536)

ANALISE E PROJETO DE SISTEMAS ORIENTADOS A OBJETOS

ARQUITETURA DE SOFTWARE

ARQUITETURA E ORGANIZ.DE COMPUTADORES (1200508)

ARQUITETURA E ORGANIZACAO DE COMPUTADORES

BANCO DE DADOS

CALCULO I

CALCULO I (1200003)

CALCULO II

CALCULO II (1200008)

CIRCUITOS DIGITAIS

COMPUTACAO GRAFICA

Fonte: Autores (2021)

A seguir é realizada a demonstração de como funciona a consulta individual de turmas. Como exemplo, foi escolhida a disciplina de Administração e Empreendedorismo.

Na Figura 25 é possível ver a tela inicial da consulta individual, quando o usuário escolhe a disciplina desejada. Na tela, são mostradas duas tabelas e um gráfico contendo as informações relacionadas ao componente. 
Figura 25 - Tela de consulta de turmas

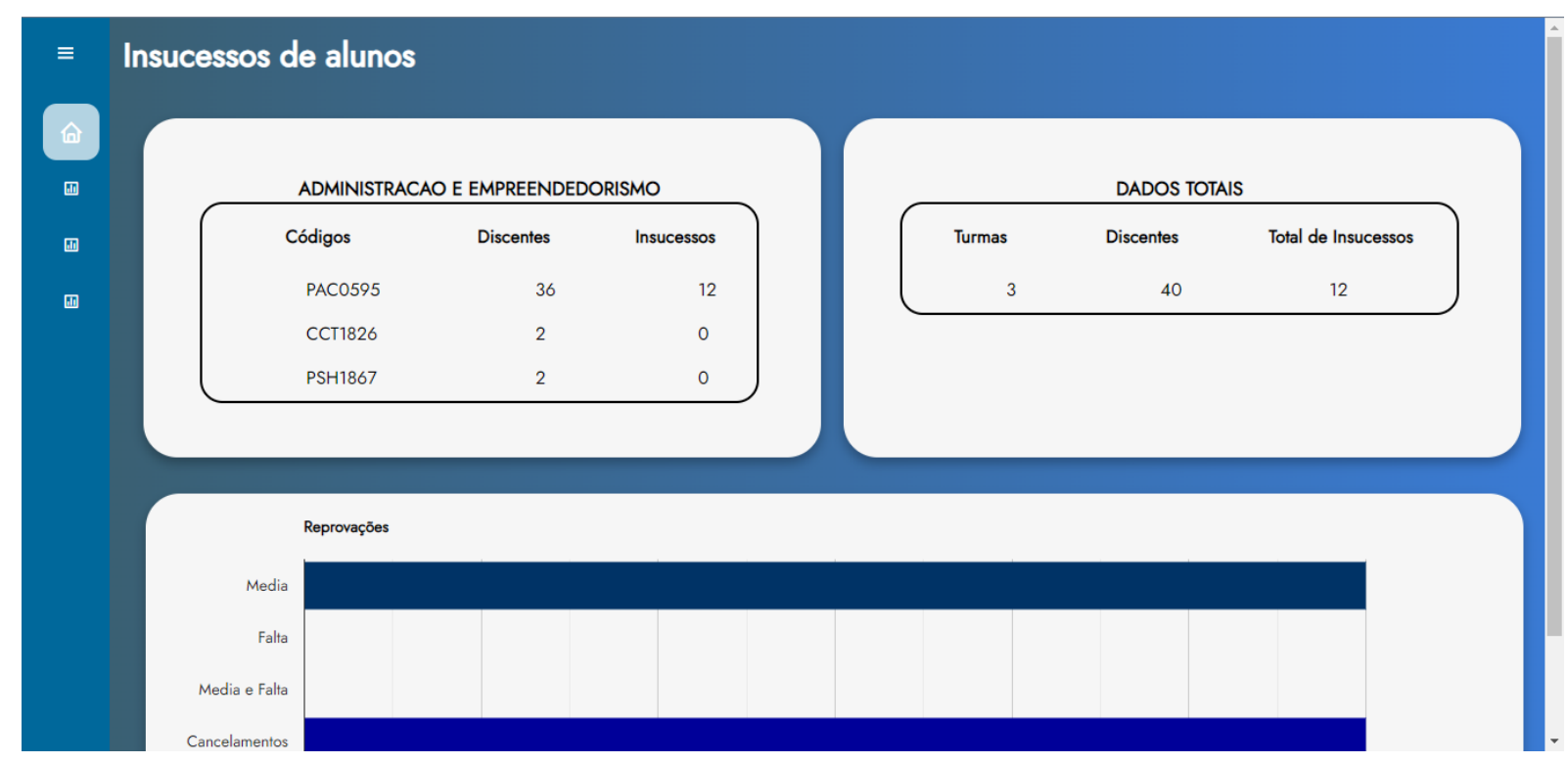

Fonte: Autores (2021)

A Tabela 1, contém dados como códigos, quantidade de discentes e insucessos da disciplina selecionada. Logo é possível visualizar que Administração e Empreendedorismo possui três turmas com códigos diferentes (PAC0595, CCT1826 e PSH1867), onde é apresentado informações de cada código de forma separada.

Tabela 1 - Dados da disciplina

ADMINISTRACAO E EMPREENDEDORISMO

Códigos

Discentes

Insucessos

PAC0595

ССT1826

2

0

PSH1867

2

0

Fonte: Autores (2021) 
Já na Tabela 2, é visualizada as informações totais da matéria, onde é realizado o somatório das turmas, dos alunos e do total de não sucessos, ou seja, ao contrário da Tabela 1, não é mostrado os dados de cada código separadamente e sim há uma unificação dos números desses códigos.

Tabela 2 - Dados gerais da disciplina

\section{DADOS TOTAIS}

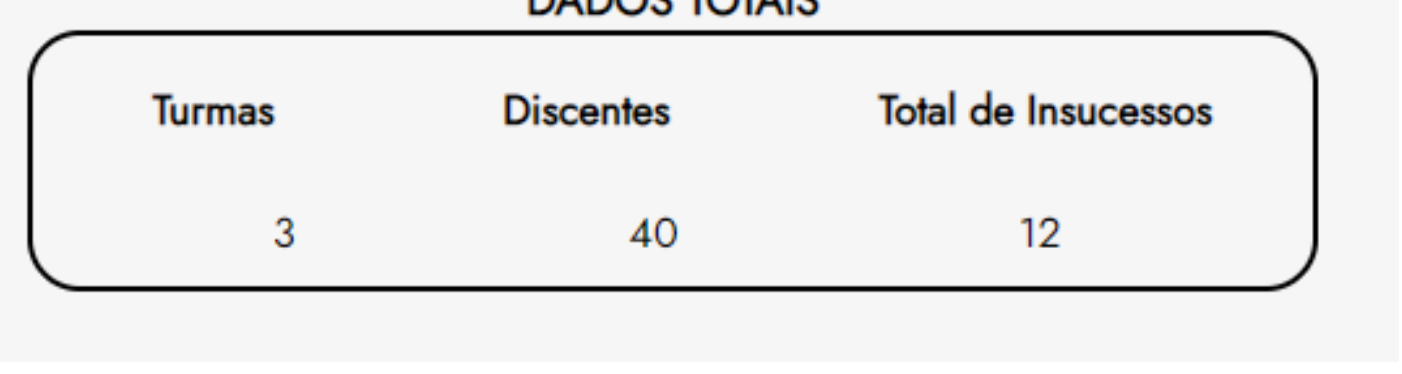

Fonte: Autores (2021)

Na Figura 26 é possível ver a quantidade de reprovações por média, faltas, média e faltas e de cancelamentos que os alunos obtiveram exclusivamente nesta disciplina. Analiticamente, é perceptível que a componente Administração e Empreendedorismo reprovou, por média, um total de 6 discentes e também 6 discentes cancelaram a mesma. Não houveram reprovações por falta e também por média e falta, simultaneamente.

Figura 26 - Reprovações

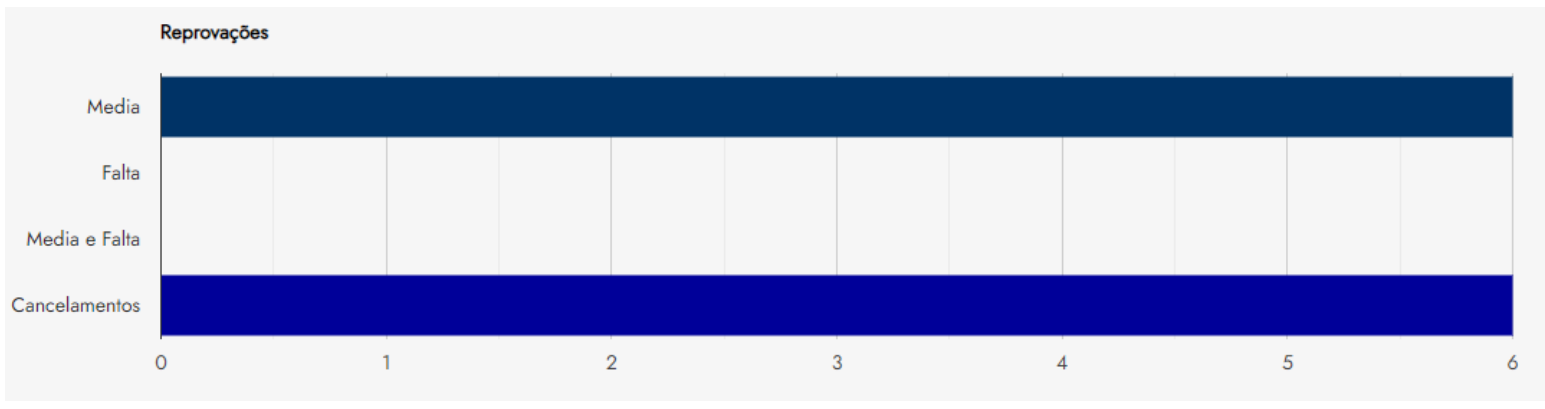

Fonte: Autores (2021) 


\section{TECNOLOGIAS UTILIZADAS}

Nesta seção são descritas as tecnologias que permitiram o desenvolvimento do ambiente descrito. Também serão descritas as plataformas utilizadas, bem como os frameworks.

\section{LINGUAGENS}

Esta seção disserta sobre as principais linguagens utilizadas para a criação do presente dashboard, e também será descrito o papel desempenhado por cada uma no desenvolvimento da ferramenta proposta.

\section{JAVASCRIPT, HTML E CSS}

O HTML (HyperText Markup Language) foi utilizado para desenvolver a estrutura básica da aplicação web. O HTML é um formato padronizado para desenvolver sistemas utilizando linguagem web, pois ele utiliza tags como marcação para inserir texto, imagem e outros conteúdos para serem exibidos no navegador (MDN, 2021).

O CSS (Cascading Style Sheets) é uma linguagem utilizada para aplicar estilos ao HTML. Essa linguagem dita como os elementos serão mostrados visualmente no navegador (MDN, 2021).

Outra linguagem utilizada para o desenvolvimento do dashboard é o JavaScript, que se tornou a principal linguagem para o sistema. O JS, como é chamado, é baseado em scripts e responsável por atribuir funcionalidades aos elementos criados através das tags em HTML (MDN, 2021).

\section{TECNOLOGIAS}

Nesta seção, são descritas as tecnologias empregadas no desenvolvimento do dashboard proposto. 


\section{NODE.JS}

De acordo com o Opus Software (2021), o Node.JS é um ambiente de execução JavaScript. Como ele é possível rodar aplicações JavaScript tanto no browser (navegador) como fora dele. Essa tecnologia é uma tecnologia assíncrona, orientada a eventos e que é capaz de atender a um grande fluxo de requisições sem bloqueio (NODE.JS, 2021).

\section{EXPRESS}

O Express é o framework Node mais popular. Ele é rápido, flexível e minimalista e possibilita usar um conjunto robusto de recursos que são de grande utilidade para desenvolver aplicações para web (EXPRESS, 2021). Existem muitas vantagens que o uso desse framework possibilita, como por exemplo soluções para o gerenciamento de requisições HTTP, integração de "view engines" para inserir dados no template, definir configurações comuns de aplicações web e definir a porta a ser utilizada para realizar a conexão (MDN, 2021).

\section{HANDLEBARS}

O HANDLEBARS é uma template engine, ou view engine, que fornece as soluções necessárias para permitir construir modelos semânticos de forma eficaz e simplificada. Essa ferramenta atribui muitas funcionalidades ao HTML, permitindo usar estruturas de repetição e condicionais, variáveis e dados provenientes do back-end diretamente no arquivo HTML (HANDLEBARS, 2021).

\section{BODY-PARSER}

O body-parser é um middleware, que serve para fazer o Express receber os dados de quaisquer formulários, XML e JSON, através de requisições HTTP (NPM, 2019). 


\section{GOOGLE CHARTS}

O Google Chars é uma biblioteca JavaScript que permite exibir dados em tempo real em aplicações web de forma simples e gratuita. Com essa ferramenta é possível plotar diversos tipos de gráficos dinâmicos para exibir os indicadores na página. Outra vantagem do Google Chars é que a sua curva de aprendizagem é pequena, isso implica na possibilidade de plotar gráficos de forma simples e que exige pouco esforço para entender o código (GOOGLE, 2021).

\section{AMCHARTS}

AmCharts é uma biblioteca de recursos de gráficos para JS, simples, poderosa e flexível, utilizada para a visualização de dados. Com essa biblioteca é possível realizar a plotagem de variados gráficos responsivos e interativos e que são compatíveis com a maioria dos navegadores modernos (AMCHARTS, 2021).

\section{XAMPP}

O XAMPP é um pacote que inclui os principais servidores de código aberto utilizados no mercado atualmente, incluindo o banco de dados MySQL. Ele é completamente gratuito e foi desenvolvido para ser fácil de instalar e utilizar (APACHE FRIENDS, 2021).

\section{GIT}

Git é um sistema de controle de versões distribuído de código aberto e gratuito, utilizado principalmente na programação de softwares. O GIT permite ter um controle de todo o código que já foi digitado, alterado e excluído (GIT, 2021). Esse software procura por alterações realizadas em arquivos e possibilita que tais alterações possam ser desfeitas ou refeitas para uma versão anteriormente digitada. 


\section{GITHUB}

O GitHub é uma plataforma que hospeda o código fonte e arquivos que possuem controle de versão utilizando o sistema Git. Essa plataforma em nuvem é essencial para programadores, pois além de hospedar códigos fonte e arquivos versionados, também permite que outros desenvolvedores colaborem e alterem o projeto de qualquer lugar do mundo (ANDREI L., 2021).

\section{SISTEMA DE GERENCIAMENTO DE BANCO DE DADOS (SGBD)}

Para gerenciar os dados que estão armazenados no Banco de Dados, é conveniente utilizar um software que irá facilitar o acesso, a persistência, a manipulação e a organização desse conjunto de informações. Um SGBD incorpora funções como definição de dados, recuperação de informações, alterações, consulta, inclusão, exclusão e atualização de dados (NASCIMENTO, 2019). Essa seção tem a finalidade de apresentar o SGBD utilizado para fazer tais funções.

\section{MYSQL}

Para o desenvolvimento do dashboard foi utilizado no banco de dados MySQL, na sua versão relacional, utilizando-se da linguagem SQL (Structured Query Language, ou Linguagem de Consulta Estruturada), sendo ela de código aberto e gratuito (MYSQL, 2021).

De acordo com o site Db-Engines (2021), é atualmente um dos principais e dos mais populares sistemas de gerenciamento de banco de dados utilizados no mundo. A flexibilidade, facilidade de uso, alto desempenho e segurança são uma das principais vantagens em utilizar esse tipo de SGBD (MYSQL, 2021). 


\section{MYSQL WORKBENCH}

O Workbench é uma ferramenta visual para arquitetura de banco de dados. Com essa ferramenta é possível projetar, desenvolver e administrar banco de dados visualmente, sem a necessidade de digitar linhas de códigos pelo terminal, além de oferecer um conjunto de outras ferramentas que melhoram o desempenho das aplicações MySQL (MYSQL, 2021).

\section{CONCLUSÕES}

Este trabalho teve por objetivo desenvolver uma ferramenta de dashboard com o intuito de monitorar e avaliar com maior precisão a situação dos discentes do curso de BTI da UFERSA para, a partir das análises, ser possível auxiliar os gestores de educação a tomarem decisões mais concisas e consistentes, sejam elas para a contratação de novos docentes, aumento de vagas em cursos ou validações de projetos que incentivem estudos em disciplinas com grandes problemas.

A grande vantagem de utilizar uma ferramenta dashboard é a facilidade de utilização, filtragem e a rapidez com que os dados são apresentados na tela do usuário em comparação com métodos tradicionais, como a utilização de planilhas, que exige uma leitura mais detalhada, lenta e exaustiva, dependendo da quantidade de informações nela contida. Além disso, esse tipo de ambiente de visualização de dados desenvolvido é ideal para lidar com quantidades massivas de dados instantaneamente e sem exigir grande poder de processamento da máquina o qual está sendo executado.

Finalmente, conclui-se que o desenvolvimento de um ambiente de visualização de informações, por meio de dashboards, pode oferecer uma solução eficiente para ajudar os gestores educacionais das IES a tomarem decisões mais satisfatórias e direcionar melhor o uso dos recursos para solucionar os problemas de evasão, egressos e retenções dos cursos por elas disponibilizadas, visto que esse tipo de ferramenta facilita a tarefa de gestão, ajudando os envolvidos a lidarem com grandes quantidades de informações de forma simples e intuitiva. Com isso, também pode-se estender as informações apresentadas nesse trabalho para outros cursos além de BTI. 


\section{REFERÊNCIAS}

AMCHARTS. JavaScript Charts \& Maps - amCharts. 2021. Disponível em: https://www.amcharts.com/. Acesso em: 03 nov. 2021.

ANDREI L. (Brasil) (ed.). O Que é GitHub e Como Usá-lo. 2021. Disponível em: https://www.hostinger.com.br/tutoriais/o-que-github. Acesso em: 03 nov. 2021.

APACHE FRIENDS. O que é o XAMPP? 2021. Disponível em: https://www.apachefriends.org/pt_br/index.html. Acesso em: 03 nov. 2021.

DB-ENGINES. DB-Engines Ranking. 2021. Disponível em: <https://dbengines.com/en/ranking>. Acesso em: 27 out. 2021.

EXPRESS. Express - Node.js web application framework. 2021. Disponível em: <https://expressjs.com/pt-br>. Acesso em: 27 out. 2021

GIT. About. 2021. Disponível em: <https://git-scm.com/>. Acesso em: 03 nov. 2021.

GOMES, Robson Ferreira. Desenvolvimento de um Dashboard para o contexto de Gestão Acadêmica. 2018. 52 f. TCC (Graduação) - Curso de Ciência da Computação, Centro Universitário Luterano de Palmas, Palmas - TO, 2018.

GOOGLE. Interactive charts for browsers and mobile devices. 2021. Disponível em: <https://developers.google.com/chart>. Acesso em: 27 out. 2021.

HANDLEBARS. Handlebars. 2021. Disponível em: <https://handlebarsjs.com>. Acesso em: 27 out. 2021.

HIPÓLITO, Oscar. O gargalo do Ensino Superior brasileiro. Entrevista concedida a Fernando Vives. Carta Capital, São Paulo, 27 abr. 2011.

KRAEMER, Johnny Rockembach. SISTEMA DE APOIO À DECISÃO PARA PREVENÇÃO DA EVASÃO NAS INSTITUIÇÕES DE ENSINO SUPERIOR. 
2018. 92 f. TCC (Graduação) - Curso de Tecnologia em Análise e Desenvolvimento de Sistemas, Universidade Tecnológica Federal do Paraná, Pato Branco, 2018.

MDN. CSS. 2021. Disponível em: <https://developer.mozilla.org/ptBR/docs/Web/CSS〉. Acesso em: 27 out. 2021.

MDN. HTML: Linguagem de Marcação de Hipertexto. 2021. Disponível em: <https://developer.mozilla.org/pt-BR/docs/Web/HTML>. Acesso em: 27 out. 2021.

MDN. Introdução Express/Node. 2021. Disponível em: $<$ https://developer.mozilla.org/pt-

BR/docs/Learn/Serverside/Express_Nodejs/Introduction>. Acesso em: 27 out. 2021.

MDN. Sobre JavaScript. 2021. Disponível em: <https://developer.mozilla.org/ptBR/docs/Web/JavaScript/About_JavaScript>. Acesso em: 27 out. 2021.

MYSQL. Why MySQL. 2021. Disponível em: <https://www.mysql.com/why-mysql>. Acesso em: 27 out. 2021.

MYSQL. MySQL Workbench. 2021. Disponível em: https://www.mysql.com/products/workbench/. Acesso em: 03 nov. 2021.

NASCIMENTO, Samara Martins. Sistemas de Bancos de Dados. Pau dos Ferros: UFERSA, 2019. 21 slides, color.

NODE.JS. Sobre Node.js. 2021. Disponível em: <https://nodejs.org/pt-br/about/>. Acesso em: 27 out. 2021.

NOVA leva de cursos tenta suprir aumento da demanda por profissionais de TI. Folha. São Paulo. dez. 2021. Disponível em: $<$ https://www1.folha.uol.com.br/mercado/2021/12/demanda-por-profissionais-de-tisupera-projecoes-e-impulsiona-iniciativas-para-suprir-deficit.shtml $>$. Acesso em: 11 dez. 2021. 
NPM.

Body-parser.

2019.

Disponível

em:

<https://www.npmjs.com/package/bodyparser>. Acesso em: 27 out. 2021.

OPUS SOFTWARE. Node.js - $\mathbf{O}$ que é, como funciona e quais as vantagens. Disponível em: https://www.opus-software.com.br/node-js/. Acesso em: 25 out. 2021.

REZENDE, Roberto Flavio. MODELO DE CRIAÇÃO DE DASHBOARDS PARA APOIO A AVALIAÇÃO DE ESTUDANTES EM AMBIENTE DE ENSINO A DISTÂNCIA. 2019. 109 f. Dissertação (Mestrado) - Curso de Informação e Sistemas Empresariais, Universidade Aberta, n.i, 2019.

Recebido em: 12/12/2021

Aprovado em: 15/01/2022

Publicado em: 19/01/2022 